\title{
Silicone v1.0.0: an open-source Python package for inferring missing emissions data for climate change research
}

\author{
Robin D. Lamboll ${ }^{1}$, Zebedee R. J. Nicholls ${ }^{2,3}$, Jarmo S. Kikstra ${ }^{1,4}$, Malte Meinshausen ${ }^{2,3}$, and Joeri Rogelj ${ }^{1,4}$ \\ ${ }^{1}$ Grantham Institute for Climate Change and the Environment, Imperial College London, UK \\ ${ }^{2}$ Australian-German Climate and Energy College, The University of Melbourne, Parkville, Victoria, Australia \\ ${ }^{3}$ School of Earth Sciences, The University of Melbourne, Parkville, Victoria, Australia \\ ${ }^{4}$ International Institute for Applied Systems Analysis, Laxenburg, Austria
}

Correspondence: Robin Lamboll (r.lamboll@imperial.ac.uk)

Received: 13 May 2020 - Discussion started: 28 May 2020

Revised: 14 September 2020 - Accepted: 23 September 2020 - Published: 4 November 2020

\begin{abstract}
Integrated assessment models (IAMs) project future anthropogenic emissions which can be used as input for climate models. However, the full list of climate-relevant emissions is lengthy and most IAMs do not model all of them. Here we present Silicone, an open-source Python package which infers anthropogenic emissions of unmodelled species based on other reported emissions projections. For example, it can infer nitrous oxide emissions in one scenario based on carbon dioxide emissions from that scenario plus the relationship between nitrous oxide and carbon dioxide emissions found in other scenarios. Infilling broadens the range of IAMs available for exploring projections of future climate change, and hence Silicone forms part of the opensource pipeline for assessments of the climate implications of IAM scenarios, led by the Integrated Assessment Modelling Consortium (IAMC). This paper presents a variety of infilling options and outlines their suitability for different cases. We recommend certain infilling techniques as good defaults but emphasise that considering the specifics of the model being infilled will produce better results. We demonstrate the package's utility with three examples: infilling all required gases for a pathway with data for only one emission species, splitting up a Kyoto emissions total into separate gases, and complementing a set of idealised emissions curves to provide a complete, consistent emissions portfolio. The code and notebooks explaining details of the package and how to use it are available on GitHub (https://github.com/ GranthamImperial/silicone, last access: 2 November 2020). The repository with this paper's examples and uses of the code to complement existing research is available at https:
\end{abstract}

//github.com/GranthamImperial/silicone_examples (last access: 2 November 2020).

\section{Introduction}

\subsection{General context and problem setting}

Integrated assessment models (IAMs) are scientific modelling tools that integrate knowledge from different academic disciplines with the aim of exploring and informing policy decisions (Clarke et al., 2014; Rogelj et al., 2018a; Weyant, 2017). They are widely used in climate change research to combine insights from energy, economy, agricultural, and natural sciences, with the aim of creating scenarios that explore how societal decisions can affect projected greenhouse gases and other emissions, as well as their related climate outcomes (Clarke et al., 2014; Huppmann et al., 2018; Riahi et al., 2017; Rogelj et al., 2018b).

However, IAMs do not always exhaustively represent all possible processes or sources of climate-relevant emissions. Thus, many IAM scenarios lack projections for some climate forcers, be it specific greenhouse gas emissions or aerosol precursors. A complete set of these climate forcers is required to accurately estimate the overall climatic effects of a given scenario (Meinshausen et al., 2011; Smith et al., 2018), as a large number of supposedly minor emissions may collectively exert a significant radiative forcing (Meinshausen et al., 2017; O'Neill et al., 2016). 
Scenarios that only report a limited set of greenhouse gases or climate forcers must thus be complemented by estimated evolutions of missing emissions derived without further economic analysis. We term this estimation "infilling". If no infilling is attempted, the unevaluated emissions would effectively be considered zero, which would clearly create systematic biases and potential artefacts in the projected temperatures. Depending on the radiative forcing of the species in question, this bias may be positive or negative, so infilling with zeros would not necessarily be a conservative choice. Most earlier studies overcame this problem in one of two ways: with expert-based ad hoc decisions on how to adequately fill in missing species (Schaeffer et al., 2015) or by assuming that a pathway will occur at the same quantile for each set of emissions in a particular year, although the quantile can vary over time (Gütschow et al., 2018; Meinshausen et al., 2006; Nabel et al., 2011). However, the former clearly does not scale easily to larger databases (because making ad hoc decisions for a thousand scenarios requires a significant time input), and the latter approach, termed the "equal quantile walk" (EQW), ignores trade-offs and specific relationships between emission species resulting from how competing technologies, behaviours, and industrial practices result in different emissions. A few alternative approaches have been used recently: for instance, using the pathway with the smallest mean squared distance over time was used in Robiou du Pont and Meinshausen (2018). This works well for large databases containing similar paths but is less reliable for smaller databases or for paths with an unusual behaviour over time. A more sophisticated "generalised quantile walk" technique can capture the effect of trade-offs and was recently introduced in Sect. 3.8.1 in Teske et al. (2019), involving quantile regression between a lead variable (fossil $\mathrm{CO}_{2}$ emissions) and other gases for every individual year. Unfortunately, the implementation there did not consistently guarantee that higher quantiles resulted in higher emissions, and has not been followed up with any peer-reviewed work that does so. A tool for infilling was provided by Rogelj et al. (2014) using a cubic spline between specific points in a small database; however, this type of infiller behaves chaotically when applied to large databases incorporating many different models. It was also coded in Excel, limiting the ease of open-source development.

Here we present a new toolbox of methods to address these recurring infilling challenges in the climatic assessment of socioeconomic emissions scenarios. The toolbox introduces new approaches as well as building on and combining previous approaches. The code base is a significant improvement compared to existing options in terms of flexibility, applicability, reproducibility, and versatility.

\subsection{The aim of Silicone}

Silicone is a Python package designed to enable users to expand scenario projections of a limited set of climate forcers to a broader set required for a sensible climate assessment. In essence, its methods are grounded in a comparison of the coevolution of anthropogenic emissions in scenarios that are readily available in the literature (Huppmann et al., 2018; Riahi et al., 2017; Rogelj et al., 2018b). Silicone aims to provide IAM teams that do not represent all individual climate forcers with robust methods to complement their model output and facilitate a climatic assessment of their work. Furthermore, Silicone also aims to provide geoscience researchers with a tool to easily develop stylised, yet internally consistent future emission pathways of the most important climate forcers. It can also estimate or calculate missing emissions from particular sectors. Notebooks describing how to use these tools are available on the accompanying GitHub repository (Lamboll et al., 2020b) and the formal documentation is available in Lamboll et al. (2020a). Additional examples of using Silicone for the specific situations outlined below are included in a separate GitHub repository (Lamboll, 2020). The package is open-source and intended to allow groups to write their own infilling methods if desired. Users and collaborators are encouraged to add any such developments to the code base via GitHub.

Silicone is compatible with a suite of Python tools that make up the IAM climate assessment pipeline developed under the umbrella of the Integrated Assessment Modelling Consortium (IAMC). Compatibility with these tools allows us to load, manipulate, and save files using a common file format. The pipeline is based around the pyam package (Gidden and Huppmann, 2019), specifically its IamDataFrame class, which Silicone makes extensive use of; pyam data frames easily convert to and from widely used pandas data frames, which pyam and Silicone also use internally (McKinney, 2011). The pipeline also includes tools to harmonise (i.e. correct projection made in the past to match now-known emissions) (called aneris; Gidden et al., 2018) before infilling and to pass the complete projections to climate simulators. The estimation of climatic impact is performed by OpenSCM (Nicholls et al., 2020), which is compatible with the data structure of the pipeline. This pipeline is being developed in support of the IAM community and the IAM scenario assessment for the forthcoming Sixth Assessment Report of the Intergovernmental Panel on Climate Change (IPCC AR6) in particular.

This paper is structured as follows: Sect. 2 presents an overview of the different infiller methods, then goes through the infiller techniques in precise and mathematical detail. In Sect. 3, we present our analysis of emissions projections in the SR1.5 database. This includes correlation statistics for the database and how well Silicone reproduces one entry in the database given the other entries. We use this to draw conclusions on the implications for using Silicone on unknown data. In Sect. 4, we present three examples of using Silicone for infilling a pathway with limited information, splitting up an aggregate basket of emissions, and infilling stylised emissions trajectories. We end with a summary of our paper. 


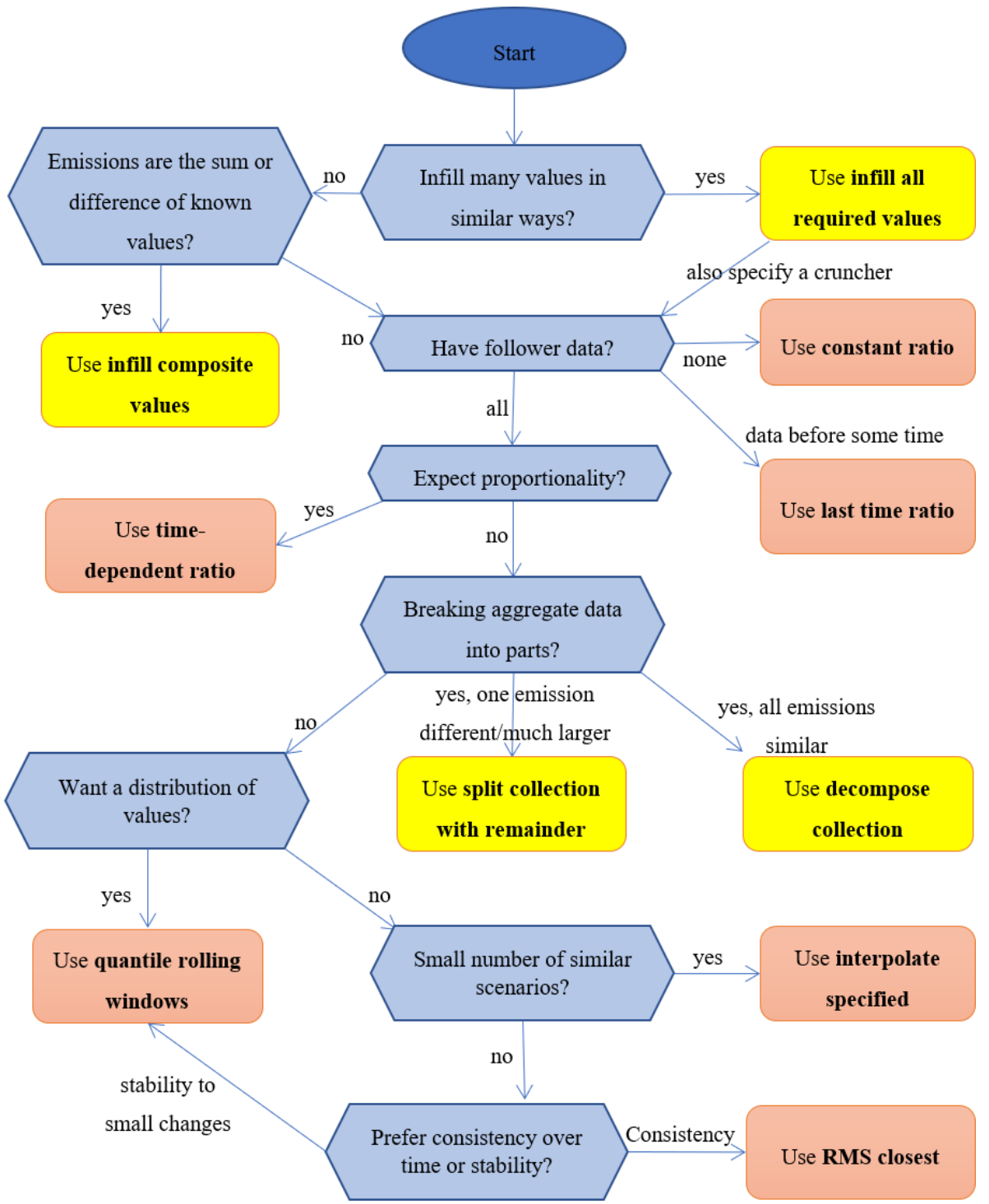

Figure 1. Flow chart suggesting how to choose the cruncher (peach oblongs) or multiple infiller (yellow oblongs) to use when infilling.

\section{Methods}

Silicone takes a database that contains data for at least two emissions species (this database is referred to as the "infiller" database) and derives a relationship between these time series. It then applies that relationship to a second database (the "target" database), which does not have any data for one of the emissions species in the infiller database. For example, based on an infiller database of $\mathrm{CO}_{2}$ and $\mathrm{N}_{2} \mathrm{O}$ emissions, Silicone could then derive $\mathrm{N}_{2} \mathrm{O}$ emissions compatible with the $\mathrm{CO}_{2}$ emissions in a less complete target database. In all cases, the infillers will perform best if the target data come from a scenario that is socioeconomically similar to scenarios found in the infiller database. The performance of most crunchers can be improved by filtering out scenarios that are known to assume radically different characteristics like population number before infilling, provided that comparable emissions statistics can be found in the remaining database.

Silicone offers a range of tools that apply methods for doing this infilling which are appropriate in different circumstances, depending on the amount of complete data and how much we know about the narrative behind our emissions. These tools are referred to as "crunchers". Each of these crunchers takes a "lead variable", found in both the infiller and target databases, and uses it to infer the value of a "follower variable", found only in the infiller database (hence missing in the target database). There are also several tools for easily infilling multiple variables, called "multiple infillers". These may have multiple follower or lead variables. 
Table 1. A guide to crunchers. Names followed by asterisks use a ratio-based approach; i.e. they find a multiplicative factor and then multiply the target lead by this value. These crunchers do not preserve harmonisation. If the asterisk is in brackets, a ratio-based approach is optional. Otherwise, techniques all return linear combinations of values seen in the infiller database.

\begin{tabular}{|c|c|c|c|}
\hline Name & Description & Use case & Pitfalls \\
\hline Constant ratio* & $\begin{array}{l}\text { Multiplies the lead variable by a } \\
\text { constant (not fitted to any data). }\end{array}$ & $\begin{array}{l}\text { Used when no information } \\
\text { about the follower variable } \\
\text { is available in any database. } \\
\text { Mainly used for infilling with } \\
\text { zeros. }\end{array}$ & $\begin{array}{l}\text { Has no basis in the data - only used as } \\
\text { a last resort in cases of complete uncer- } \\
\text { tainty. }\end{array}$ \\
\hline Latest time ratio* & $\begin{array}{l}\text { Multiplies the lead variable by } \\
\text { a constant fitted to a single } \\
\text { (latest) time point in the infiller } \\
\text { data. }\end{array}$ & $\begin{array}{l}\text { Used when no data are available } \\
\text { for most times; this generalises } \\
\text { from the latest information we } \\
\text { have, e.g. if only historic data } \\
\text { are available. }\end{array}$ & $\begin{array}{l}\text { No reason to assume that the rela- } \\
\text { tionship between emissions holds for } \\
\text { all times. No restriction on signs of } \\
\text { follower gas, so potential sign errors } \\
\text { when the lead (but not follower) emis- } \\
\text { sions may become negative. Sensitive } \\
\text { to emissions trajectories with a high co- } \\
\text { efficient of variation. }\end{array}$ \\
\hline
\end{tabular}

Time-dependent ratio* Multiplies the lead variable by the ratio of the averages of the lead and follower data in the infiller database. (Note: this ratio is not the same as the average of the ratios and is more stable to inclusion of extreme ratios.) Optionally calculates this using only values with the same sign of lead emissions.

Finds the most similar path-
way in the infiller database and uses those values. Most similar means smallest root mean squared difference between the lead values of infiller pathways and target pathway averaged over all times.
Used when two emissions should track each other or one represents a portion of the other.
Allows arbitrarily high emissions. Can behave unexpectedly if emissions change sign, and an error is produced if emissions with this sign are not seen at the same time in the infiller database.
Used when behaviour at one time should strongly determine behaviour at another and continuity is needed between times. The only cruncher that does not treat each time separately.
A small change in the target data at a single time step can result in large changes in output at every time step. All the results returned are found exactly in the infiller database, so if that database is small, the same values are returned in many cases. Results more extreme than those found in the infiller database all return the same value.
Linear interpolation; interpolate specified scenarios and models
At each time, linearly interpolates between the follower values at the two nearest lead values, taking averages where multiple points have identical lead values. Interpolates specified scenarios and models filters in the infiller database before applying the same technique.
Used for infilling where we have a small number of comparable models and/or scenarios. The required filtering gives control over the narrative used for infilling.
A small change in the target data can result in a large change in the output at the same time step because pathways in the infiller database can be very different in follower variables for nearly identical values of the lead variable. For similar reasons, results can vary erratically between time steps for large infiller datasets. Results more extreme than those found in the infiller database all return the same value. 
Table 1. Continued.

\begin{tabular}{|c|c|c|c|}
\hline Name & Description & Use case & Pitfalls \\
\hline $\begin{array}{l}\text { Equal quantile walk } \\
(\mathrm{EQW})\end{array}$ & $\begin{array}{l}\text { Calculates the quantile of the } \\
\text { infiller database corresponding } \\
\text { to the lead value in each indi- } \\
\text { vidual year. Returns that quan- } \\
\text { tile in that year of the follower } \\
\text { value from the same database. }\end{array}$ & $\begin{array}{l}\text { Conceptually simple, used by } \\
\text { previous work. }\end{array}$ & $\begin{array}{l}\text { Assumes all variables are monotoni- } \\
\text { cally increasing together. Results more } \\
\text { extreme than those found in the infiller } \\
\text { database all return the same value. }\end{array}$ \\
\hline
\end{tabular}

\subsection{Methods overview}

\subsubsection{Cruncher guide}

There are currently seven types of cruncher. These are outlined in Table 1 below. A flow chart to guide the choice is shown in Fig. 1. There is also a series of notebooks with examples of how to use them all in the main GitHub repository (Lamboll et al., 2020b).

\subsubsection{Multiple infiller and aggregation tool guide}

Multiple infillers are for cases in which there are relationships between multiple lead or follower values that need to be considered at the same time. They allow less tailored approaches to infilling but can ensure that the infilling is faster or more consistent than infilling each of the variables separately. These are outlined in Table 2 .

\subsection{Mathematical detail}

Notebooks presenting the benefits and risks of each cruncher type can be found in the Silicone GitHub (Lamboll et al., 2020b) and may be useful to have as examples when analysing the work below, as well as demonstrating how to use them.

There are two main classes of infillers: those based on the ratios between two emission pathways and those based on the absolute emission values in the infiller database. If the results are to be harmonised, then harmonising both the infiller and target data before infilling is required for improved consistency (otherwise, infilling depends on outdated data). Absolute value infilling techniques preserve harmonisation; however, ratio-based approaches do not necessarily do this and may need harmonisation again afterwards.

The ratio-based approaches are better for cases in which the lead values to be infilled are outside the range in the infiller database and we expect the emissions to scale with each other, for instance if we are infilling one incomplete combustion product based on another or splitting up aggregated emissions into their components. However, care needs to be taken when infilling emissions that are non-negative using a lead value that may be of any sign, for example $\mathrm{CO}_{2}$ emissions. In that case, the ratio method might produce values for the target emissions that are unsupported by any available evidence. Singular behaviour may also be encountered when the lead data are close to zero in the infiller database. The different crunchers present different ways to estimate the ratio to use.

The absolute-value-based techniques infill with values derived from the absolute data found in the infiller database or linear combinations of them. This means that they will always return values within the range spanned by the infiller database. This is most appropriate for processes whereby we have a greater number of cases, preferably with both larger and smaller lead emissions in the infiller database or when we expect the follower emissions to be strongly bounded rather 
Table 2. Guide to aggregation tools and multiple infillers. Names followed by asterisks use a ratio-based approach; i.e. they find a multiplicative factor and then multiply the target lead by this value. If the asterisk is in brackets they are ratio-based.

\begin{tabular}{|c|c|c|c|}
\hline Name & Description & Use case & Pitfalls \\
\hline \multicolumn{4}{|l|}{ Aggregation tools } \\
\hline $\begin{array}{l}\text { Aggregate to composite } \\
\text { values }\end{array}$ & $\begin{array}{l}\text { Requires only the target } \\
\text { database. Adds together known } \\
\text { values to construct a consistent } \\
\text { output (with optional weight- } \\
\text { ing). }\end{array}$ & $\begin{array}{l}\text { Infilling aggregate values (e.g. } \\
\text { Kyoto gas totals) or finding re- } \\
\text { mainders given aggregates and } \\
\text { values for the other compo- } \\
\text { nents. }\end{array}$ & $\begin{array}{l}\text { Requires all information to be } \\
\text { known already - no statistical } \\
\text { inference, just adding. }\end{array}$ \\
\hline \multicolumn{4}{|l|}{ Multiple infillers } \\
\hline $\begin{array}{l}\text { Decompose collection } \\
\text { with time-dependent } \\
\text { ratio* }\end{array}$ & $\begin{array}{l}\text { Constructs a consistent version } \\
\text { of the aggregate in the in- } \\
\text { filler database. Breaks a known } \\
\text { quantity down into compo- } \\
\text { nents, estimated by the time- } \\
\text { dependent ratio method. }\end{array}$ & $\begin{array}{l}\text { Breaking down aggregate val- } \\
\text { ues into their components, as- } \\
\text { suming all should be treated } \\
\text { similarly. }\end{array}$ & $\begin{array}{l}\text { Infiller scenarios which do not } \\
\text { have values for all compo- } \\
\text { nents at all times are ignored. } \\
\text { Ignores the aggregate if the } \\
\text { infiller database has inconsis- } \\
\text { tency between that and the sum } \\
\text { of reported components. As- } \\
\text { sumes direct proportionality be- } \\
\text { tween components and sum, } \\
\text { which is problematic around } \\
\text { sign changes. }\end{array}$ \\
\hline $\begin{array}{l}\text { Split collection with } \\
\text { remainder emissions }\end{array}$ & $\begin{array}{l}\text { Breaks an aggregate emission } \\
\text { into most of its separate com- } \\
\text { ponents, with one emission type } \\
\text { making up the remainder of the } \\
\text { emissions. }\end{array}$ & $\begin{array}{l}\text { Breaking down aggregate val- } \\
\text { ues into their components when } \\
\text { one emission type is much } \\
\text { larger than the others or may be } \\
\text { either positive or negative }\end{array}$ & $\begin{array}{l}\text { The remainder emission is not } \\
\text { constrained nor as precisely es- } \\
\text { timated as the other values. }\end{array}$ \\
\hline $\begin{array}{l}\text { Infill all required values } \\
\left({ }^{*}\right)\end{array}$ & $\begin{array}{l}\text { Uses the same lead variable and } \\
\text { cruncher to infill any gaps in } \\
\text { emissions data. }\end{array}$ & $\begin{array}{l}\text { For infilling scattered, } \\
\text { minor gaps in a largely sound } \\
\text { database. }\end{array}$ & $\begin{array}{l}\text { Low confidence in the results } \\
\text { being accurate as the method } \\
\text { does not consider the specific } \\
\text { characteristics of the data. }\end{array}$ \\
\hline
\end{tabular}

than increasing in line with other variables. They may be considered more stable and more conservative. The quantilerolling-windows (QRW) cruncher can be used in either ratio or absolute (non-ratio) mode, the absolute mode being the default.

As one final detail, we discuss the data model which is assumed by Silicone. Silicone is built around the pyam package (Gidden and Huppmann, 2019). As a result, it assumes that all input data are provided in a particular structure. The structure includes the model which created the time series, the scenario with which the time series is associated (e.g. a high BECS $1.5^{\circ}$ scenario), the region the emissions occurs in, and the unit of the data (full details available at https: //pyam-iamc.readthedocs.io/en/stable/data.html, last access: 2 November 2020). Accordingly, Silicone is able to work on specific subsets of models (e.g. only the MESSAGE model) or subsets of scenarios (e.g. all SSP1-like scenarios). We therefore follow the pyam convention and refer to a "modelscenario combination" to mean a single projected world that in some contexts might be called a "scenario".
Pyam data frames assign values to variables as a function of different models, scenarios, regions, and times. All methods work on databases with only a single region at a time, although the region can be different between the infiller and target databases.

\subsubsection{Ratio infilling methods}

These methods all firstly estimate the ratio of the lead variable to the follower variable. In all cases, we first determine the ratios, written as $R(t)$ at time $t$. Once these have been calculated, the follower value in the target database, $E_{f}(t)$, is valued as

$E_{f}(t)=R(t) E_{1}(t)$,

where $E_{1}(t)$ is the lead value in the target database.

\section{Constant-ratio and latest-time-ratio crunchers}

Constant-ratio and latest-time-ratio methods both use the same ratio for all infill times, $R(t)=R$. With the constantratio method, the ratio must be given as an input parameter. 
The latest-time-ratio method uses the ratio between the mean follower data in the infiller database (we denote this database with lower-case $e_{f}$ ) and the value of the lead variable in the target data $\left(E_{1}\right)$, with both values evaluated at the latest time for which there are follower data in the infiller database, $t_{\text {last }}$. The mean is taken over all infiller data at that time. This is designed for the case in which we have estimates only until a certain time, after which they stop - for instance, if we have no projections for some new hydrofluorocarbon (HFC) emissions, but we have historic measurements for recent years. This gives us the equation

$R=\frac{\left\langle e_{f}\left(t_{\text {last }}\right)\right\rangle}{E_{1}\left(t_{\text {last }}\right)}$,

where the angular brackets mean taking the (algebraic) mean with equal weighting for all estimates (typically historical estimates) at that time and with a lower-case $e_{f}(t)$ representing the follower values in the database at time $t$. This ensures that at $t_{\text {last }}$, all infilled data will fulfil

$E_{f}\left(t_{\text {last }}\right)=R \times E_{1}\left(t_{\text {last }}\right)=\left\langle e_{f}\left(t_{\text {last }}\right)\right\rangle$.

\section{Time-dependent ratio cruncher}

The time-dependent ratio is appropriate when there are some data in the infiller database for all times and allows the ratio to vary with time. The ratio used is

$R(t)=\frac{\left\langle e_{f}(t)\right\rangle}{\left\langle e_{1}(t)\right\rangle}$.

Optionally, the averaging can be taken only over modelscenario cases in which the sign of the lead variable is the same in both the infiller and target case - this will guarantee that the infilled value takes the same sign as that of follower values in the database. It will produce an error if there are no data with the required sign. This cruncher has a useful conservativity property (with or without the sign restriction): if in every scenario averaged over, the emissions of several substances sum to another substance, e.g. if $e_{1}=e_{2}+e_{3}$, then $\left\langle e_{1}\right\rangle=\left\langle e_{2}\right\rangle+\left\langle e_{3}\right\rangle$. It then follows that

$1=\frac{\left\langle e_{2}\right\rangle}{\left\langle e_{1}\right\rangle}+\frac{\left\langle e_{3}\right\rangle}{\left\langle e_{1}\right\rangle}$

the right-hand side of which we can identify as the two $R(t)$ values of using Eq. (3) twice for different followers. This means when the aggregate is the lead and the components are followers, the sum of the two ratios is 1 , so we can use this infiller to break an aggregate value into components and know that the total is conserved. This relationship generalises to any number of components, still holds when emissions can be negative, and is irrespective of whether the averaging includes all values or only those for which the lead has a particular sign.

This cruncher is the foundation for the "decompose collection with time-dependent ratio" multiple infiller. This relies on all scenarios having values for all of these variables, so misses it cases which do not have one of the constituents or only reports at some of the required times, unless the override option only_consistent_cases is set to false. It always constructs a new, consistent version of the aggregate variable in case different modellers used different conversion factors in the infiller database.

\section{Quantile-rolling-window cruncher}

The quantile-rolling-window method may be applied in ratio mode, in which case we calculate $R(t)$ by first calculating the ratio for each scenario,

$r_{\mathrm{s}}(t)=\frac{e_{f}(t)}{e_{1}(t)}$

then following the calculation in the absolute value section using this instead of $e_{1}$. This method finds quantiles of the ratio in the infiller database at set points along the range of lead values in the infiller database.

\subsubsection{Absolute value infilling methods}

\section{RMS-closest cruncher}

The RMS-closest cruncher filters the infiller database for models with data at all the times found in the target data. It then ranks models and scenarios by the root mean squared (RMS) difference between the lead data in the infiller and target database, with the average being taken over all time slices. It returns the follower data from the scenario-model combination with the smallest RMS difference: the formula is $E_{f}(t)=e_{f, i}(t)$, where the subscript $i$ refers to the modelscenario case that minimises

$\sum_{t}\left(E_{1}(t)-e_{f, i}(t)\right)^{2}$

In the case of a draw, the value that occurs earlier in the infiller database will be used. This is the only infiller that is not time-independent; i.e. changing the value of the lead at one time may result in different outputs at other times.

\section{Linear interpolation}

The linear interpolation method constructs a linear (unsmoothed) interpolator function between all lead and follower points in the infiller database at a given point in time. It is similar in concept to the cubic spline interpolator used in Rogelj et al. (2014). The equation for our case is

$$
E_{f}(t)=e_{f<}(t)+\left(E_{1}(t)-e_{1<}(t)\right) \frac{e_{f>}(t)-e_{f<}(t)}{e_{1>}(t)-e_{1<}(t)^{\prime}},
$$

where subscript $<$ or $>$ signs indicate the model-scenario combination with lead values immediately below or above the target lead value at that time. If multiple points have exactly the same lead value, the average follower value is used. 
The follower value returned is then the interpolated value for the target lead. The "interpolate specified scenarios and models" cruncher filters for scenarios and models that match a given text string before performing the same action of the linear interpolation cruncher.

\section{Quantile-rolling-windows cruncher}

The quantile-rolling-windows cruncher, applied with the default option use_ratio=false, infills the values based on interpolating between the required quantile of the follower variable. This is calculated at fixed points across the range of lead values in the infiller database for each time. The process is identical to the above discussion wherein use_ratio is true, except using the actual follower values instead of the ratios between lead and follow. It is inspired by the generalised quantile walk approach in Sect. 3.8.1 of Meinshausen and Dooley (2019). An illustration of the idea behind this cruncher is shown in Fig. 2. For each time in the infiller database, it splits the range of lead values into $n_{\text {windows }}$ points (defaults to 10) with values $e_{p}$, including the highest and lowest values. For each window, the weightings of each point are given as

$w_{p}\left(e_{1}(i)\right)=1 /\left(1+\left(\left(e_{p}-e_{1}(i)\right) / d_{1}\right)^{2}\right)$,

where $d_{1}$ is the decay length, which defaults to half the separation between $e_{p}$ values, and $i$ is the label for which model-scenario we are investigating. Increasing the decay length will reduce the weight difference between points, so the rolling window becomes wider and more even, with the limit case of calculating quantile $q$ of all data for large $d_{1}$. Amongst other things, this is a clear improvement over the generalised quantile walk approach, as the latter uses equal weights within a fixed window of a certain fraction of the infiller database's lead values in a certain year. These values are then normalised so that $\sum w_{p}=1$ and sorted into ascending order by $e_{f}$. The follower value at quantile $q$, evaluated at lead point $e_{1}(j)$, is where the quantile equals the sum of weights of all smaller $e_{f}$ plus half the weight of $e_{f}(j)$ itself. Note that we sum over smaller follower values, but the weighting is determined by the lead values:

$q\left(e_{1}(j)\right)=\sum_{e_{f}(i)<e_{f}(j)} w_{p}\left(e_{1}(i)\right)+\frac{w_{p}\left(e_{1}(j)\right)}{2}$.

Quantiles between these are evaluated by linearly interpolating this relationship. We are usually interested in the case in which $q=0.5$. To infill a point at $E_{1}$, we interpolate between the known points $e_{p}$. Quantile crossing is not possible in this framework because at any given evaluation point higher quantiles cannot have lower values, and only linear fits between these points are used.

\section{Equal quantile walk}

The equal quantile walk calculates the quantile of the lead value at each time (Meinshausen et al., 2006). This is zero
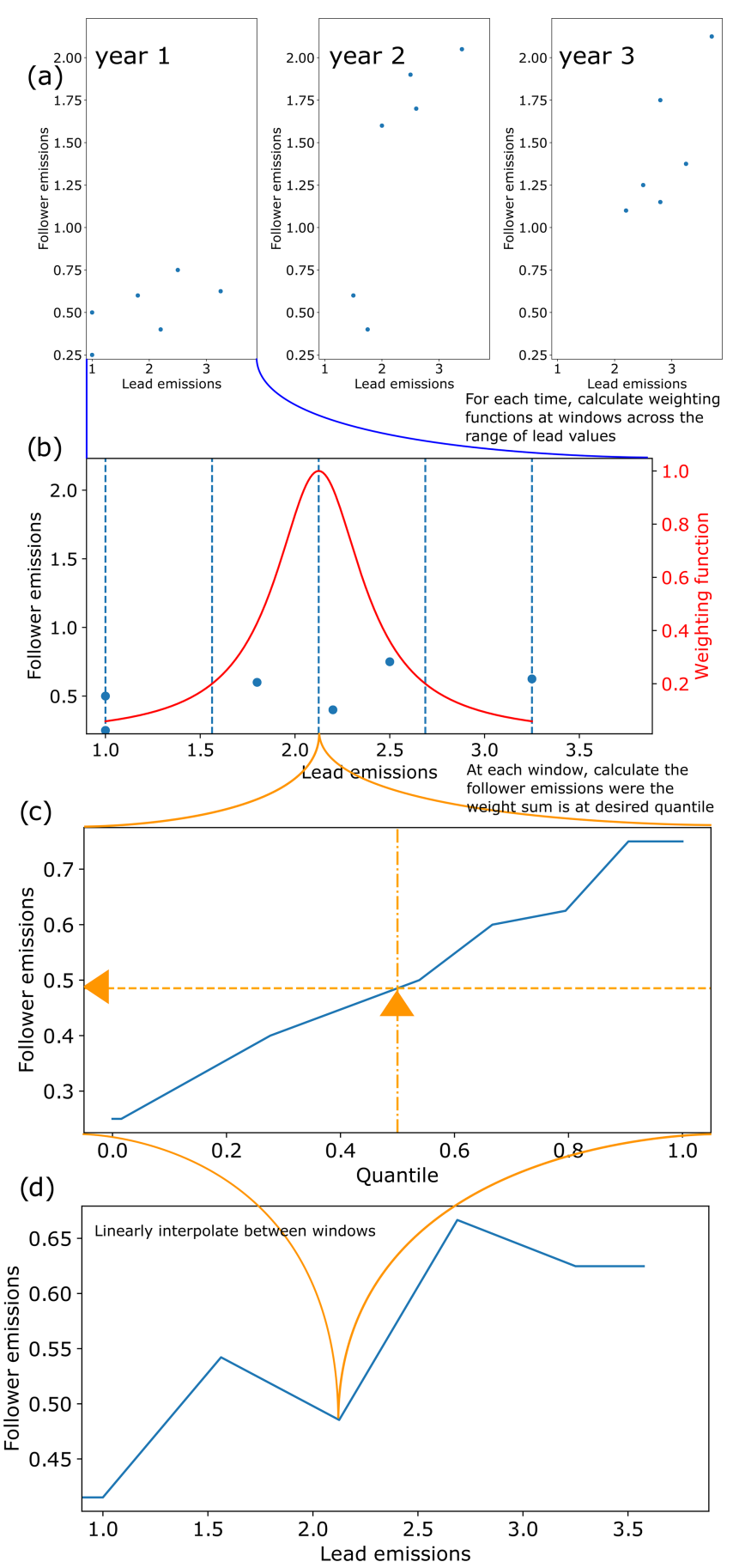

Figure 2. Schematic of how the quantile-rolling-windows cruncher determines the follower value to use. (a) Example relationships between lead $\left(\mathrm{CO}_{2}\right)$ and follower $\left(\mathrm{CH}_{4}\right)$ variables over time. (b) A number of rolling window centres (here 5 , by default 10) are drawn, and a weighting function is constructed for each window. It has a continuous distribution rather than a discrete cutoff, hence the name. (c) A relationship between the sum of the weights and the follower value is established, and the follower value at the desired quantile is returned. 
for values below the database minimum, 1 for those above the database maximum, and the fraction of infiller data smaller or equal to this value otherwise. We interpolate between neighbouring values in the infiller data to find the fraction that would match the target value exactly. We then apply the same logic to calculate the appropriate value for the derived quantile of the follower data.

\subsection{General limitations}

Note that all of the methods listed above are purely statistical in nature: if the scenarios in the infiller database are fundamentally different from those in the target database, different relationships are likely and the validity of the results is poor. The adequate use of Silicone requires users to select an infiller database most appropriate for each respective application. Using Silicone with an infiller database that has itself been infilled may distort the model democracy of the results. Note also that in version 1.0.0 of Silicone, all methods take only a single lead value, although forthcoming work will add the capacity to use multiple lead values to some crunchers. This will improve the ability to resolve more complex relationships, since it is possible for very different worlds to have similar emission trends in one emission without being similar in other emissions.

\section{Results}

\subsection{Rank correlations}

The infilling method is important. However, equally important is the choice of lead variable. The best choice is where there is a causal link between the lead and follower variable, particularly if there is a clear understanding of the implications of this link for the relative behaviour of the two variables; for instance, black carbon and carbon monoxide are both produced by incomplete combustion. In most cases, there is no such certainty, and the best choice is then to find the lead variable with the best predictive power. We estimate this by the Spearman's rank correlation coefficient, a measurement of the monotonicity of the relationship between the two variables. In cases in which this value is low, we anticipate the need for higher effort to select relevant cases from the infilling database. We use the data from the IPCC Special Report on Global Warming of $1.5^{\circ} \mathrm{C}$ (Huppmann et al., 2018) as our database of scenarios and compare the correlations between the different variables. The Silicone package has a function in the statistics section called calc_all_emissions_correlations, which will produce tables of both the Spearman (rank) and Pearson correlation coefficients, calculated separately for each year requested, and the time-averaged magnitude of the correlations. Since there is no reason to expect the relationships between variables to be linear, we will focus on the rank correlation in this analysis. We also plotted the relationships between $\mathrm{CO}_{2}$ and all other variables (using the plotting function in the Silicone examples on GitHub) to check that there were no obvious cases of a non-monotonic relationship. All the crunchers work just as well with negative trends as with positive, so the sign of the correlations is not relevant for considering goodness of fit. Using this tool, we can calculate the decadal-averaged magnitude of the rank correlation coefficient, found in Table 3. We also calculate the variation of this value with time, and in cases in which this exceeds 0.03 (chosen to highlight only extreme cases) we write the values with asterisks. This is to indicate cases in which more care needs to be taken to ensure that values are representative for the times of interest.

The immediate observation from the study of absolute rank correlations is that there is no clear, overall best infiller gas. $\mathrm{CH}_{4}$ has a slightly higher average than other emissions and is reported by most models. $\mathrm{CO}_{2}$ is reported by all models and has the second-highest correlation; however, this is somewhat inflated by having two of its constituents listed separately (agriculture, forestry, and other land use - AFOLU - and energy and industrial processes; a similar concern can be raised about $\mathrm{F}$ gases). Generally, $\mathrm{CO}_{2}$ and $\mathrm{CH}_{4}$ are therefore the best choices for a default lead variable. However, there are some specific cases in which the correlations are low, and much better choices could be made.

There is a cluster of emissions species, specifically black carbon, organic carbon, and carbon monoxide, that correlate well with each other but less well with other emission pathways. Physically, these relate to incomplete burning and are best infilled using each other. The $\mathrm{F}$ gases, $\mathrm{SF}_{6}$, hydrofluorocarbons (HFCs), and perfluorinated compounds (PFCs) also primarily relate to each other. Many models report Fgas emissions as a basket. Infilling these should best be done by splitting the F-gas basket into its constituents. Otherwise, the default infillers, $\mathrm{CO}_{2}$ and $\mathrm{CH}_{4}$, should do reasonably.

\subsection{Reconstructing data}

The choice of cruncher to use in different situations will depend on the expectations about the specific emissions in question. However, in cases in which there are no clear expectations, it is good to have a default. In this section we assess to what degree the cruncher reproduces the follower data from one model and scenario given the lead data from that case and all data from all the other model-scenario combinations in the SR1.5 database. We try this with both $\mathrm{CH}_{4}$ and $\mathrm{CO}_{2}$ as our lead variables. We use the crunchers that are designed for use on complete datasets with only default settings: QRW (default settings mean in absolute mode and for the 0.5 quantile), RMS closest, EQW, time-dependent ratio, and linear interpolation. "Interpolate selected model" behaves identically to linear interpolation with default settings and is not treated separately here. We perform the infilling for each model-scenario combination for each decade from 2020 to 2100 and report the root mean squared difference between the original value and the infilled value, normalised by 
Table 3. Absolute values of Spearman's rank correlation between emissions, averaged over the start of decades from 2020 to 2100 . We use the following abbreviations: BC as black carbon; VOCs as volatile organic compounds; AFOLU as agriculture, forestry, and other land use; and En \& IP as energy and industrial processes. " $\mathrm{CO}_{2}$ " " represents subtypes of $\mathrm{CO}_{2}$. We also calculate the average of these rows, with or without the $\mathrm{CO}_{2}$ and subtypes. Cells are bold if the value in them is $>0.7$ and have asterisks if the variance of the rank correlation between years exceeds 0.03 . There is no overlap between these categories.

\begin{tabular}{|c|c|c|c|c|c|c|c|c|c|c|c|c|c|c|c|c|}
\hline Variable & $\mathrm{BC}$ & $\mathrm{CH}_{4}$ & $\mathrm{CO}$ & $\mathrm{CO}_{2}$ & $\mathrm{CO}_{2} \mid \mathrm{AFOLU}$ & $\mathrm{CO}_{2} \mid$ En \& IP & $F$ gases & HFC & $\mathrm{N}_{2} \mathrm{O}$ & $\mathrm{NH}_{3}$ & $\mathrm{NO}_{x}$ & OC & PFC & $\mathrm{SF}_{6}$ & Sulf & VOCs \\
\hline $\mathrm{BC}$ & & 0.47 & 0.75 & 0.46 & 0.37 & 0.42 & 0.23 & 0.10 & 0.40 & 0.40 & 0.58 & 0.73 & 0.41 & 0.20 & 0.48 & $0.45^{*}$ \\
\hline $\mathrm{CH} 4$ & & & 0.32 & 0.74 & 0.49 & 0.73 & $0.64^{*}$ & 0.58 & 0.86 & 0.34 & 0.58 & 0.30 & 0.66 & 0.41 & 0.65 & 0.24 \\
\hline $\mathrm{CO}$ & & & & 0.36 & 0.38 & 0.32 & 0.06 & $0.16^{*}$ & 0.29 & 0.35 & 0.48 & 0.78 & 0.05 & 0.17 & 0.36 & 0.68 \\
\hline $\mathrm{CO} 2$ & & & & & 0.54 & 0.96 & 0.60 & 0.57 & 0.54 & 0.30 & 0.61 & 0.24 & 0.35 & $0.22 *$ & 0.69 & 0.37 \\
\hline $\mathrm{CO} 2 \mid \mathrm{AFOLU}$ & & & & & & 0.36 & 0.27 & $0.40^{*}$ & 0.53 & 0.36 & 0.33 & 0.34 & $0.23^{*}$ & $0.21^{*}$ & 0.31 & 0.20 \\
\hline $\mathrm{CO} 2 \mid \mathrm{En} \& \mathrm{IP}$ & & & & & & & $0.58^{*}$ & 0.51 & 0.50 & 0.25 & 0.61 & 0.17 & $0.32 *$ & $0.18^{*}$ & 0.69 & 0.36 \\
\hline$F$ gases & & & & & & & & 0.91 & 0.57 & 0.19 & 0.50 & 0.10 & 0.90 & 0.77 & 0.60 & 0.12 \\
\hline HFC & & & & & & & & & 0.46 & 0.11 & 0.30 & 0.14 & 0.71 & 0.68 & 0.36 & 0.23 \\
\hline $\mathrm{N} 2 \mathrm{O}$ & & & & & & & & & & $0.44^{*}$ & 0.46 & 0.30 & 0.65 & 0.40 & 0.49 & 0.17 \\
\hline NH3 & & & & & & & & & & & 0.23 & 0.39 & 0.10 & 0.05 & 0.23 & 0.25 \\
\hline NOx & & & & & & & & & & & & 0.22 & 0.53 & 0.26 & 0.76 & 0.39 \\
\hline OC & & & & & & & & & & & & & 0.20 & 0.11 & $0.19^{*}$ & 0.41 \\
\hline PFC & & & & & & & & & & & & & & 0.77 & 0.46 & 0.16 \\
\hline SF6 & & & & & & & & & & & & & & & $0.26^{*}$ & 0.24 \\
\hline Sulfur & & & & & & & & & & & & & & & & $0.46^{*}$ \\
\hline \multicolumn{17}{|l|}{ VOCs } \\
\hline Average & 0.43 & 0.53 & 0.37 & 0.50 & 0.36 & 0.46 & 0.47 & 0.42 & 0.47 & 0.27 & 0.46 & 0.31 & 0.43 & 0.33 & 0.47 & 0.32 \\
\hline Average, no $\mathrm{CO}_{2}$ & 0.43 & 0.50 & 0.37 & 0.46 & 0.34 & 0.43 & 0.47 & 0.40 & 0.46 & 0.26 & 0.44 & 0.32 & 0.47 & 0.36 & 0.44 & 0.32 \\
\hline No. scenarios & 389 & 412 & 353 & 414 & 412 & 414 & 368 & 108 & 411 & 345 & 363 & 363 & 180 & 191 & 412 & 345 \\
\hline
\end{tabular}

the standard deviation in the follower value in the database at that time $(\sigma)$, i.e. $\left\langle\sqrt{\left\langle\left(\frac{E_{f, \text { inf }}-E_{f, \text { act }}}{\sigma}\right)^{2}\right\rangle}\right\rangle_{i}$, with the subscript text "inf" indicating that the value is infilled, "act" indicating actual, and $i$ /decade indicating averaging over modelscenario cases or decades. These results are found in Tables 4 and 5. Given the definition of standard deviations, values larger than 1 would indicate that this infiller is worse than simply using the mean value in the database.

We see with this fairly large infiller database that for both $\mathrm{CO}_{2}$ and $\mathrm{CH}_{4}$ the approach that generates follower pathways most similar to those removed from the initial scenarios (i.e. the smallest errors) is the RMS technique, with the QRW technique being the next smallest. Linear interpolation without smoothing is expected to produce a noisy fit when given a large infiller dataset, so its performance is unsurprisingly worse. The equal quantile walk (EQW) performs similarly poorly due to effectively ignoring the relationship between the lead and follower data. The time-dependent ratio method is worst of all - its errors are potentially unbounded and for $\mathrm{CO}_{2}$ the average error far exceeds 1 . To determine the appropriate statistics to apply on the errors, we first perform a Shapiro-Wilk test to detect any non-Gaussian aspect for the error distribution (details can be found in the statistics_for_ paper notebook of the examples on the GitHub repository). This indicated that the distributions are statistically significantly non-Gaussian for several crunchers when analysed separately and most clearly as an aggregate. We will therefore use non-parametric tests where possible. The small differences in rank between $\mathrm{CH}_{4}$ and $\mathrm{CO}_{2}$ manifest in slightly lower values for $\mathrm{CH}_{4}$. Performing a Wilcoxon's $t$ test on
Table 4. Root mean squared error in reconstructing known data using different crunchers, with $\mathrm{CO}_{2}$ as the lead variable, normalised by the standard deviation at that time.

\begin{tabular}{lrrrrr}
\hline & $\begin{array}{r}\text { Time- } \\
\text { dependent } \\
\text { ratio }\end{array}$ & $\begin{array}{r}\text { RMS } \\
\text { QRW }\end{array}$ & $\begin{array}{r}\text { Linear } \\
\text { Closest }\end{array}$ & $\begin{array}{r}\text { Inter- } \\
\text { polation }\end{array}$ & EQW \\
\hline $\mathrm{BC}$ & 1.763 & 0.734 & 0.668 & 1.021 & 0.921 \\
$\mathrm{CH}_{4}$ & 0.774 & 0.460 & 0.392 & 0.520 & 0.500 \\
$\mathrm{CO}$ & 2.236 & 0.804 & 0.764 & 1.049 & 1.006 \\
$\mathrm{~F}$ gases & 0.576 & 0.537 & 0.485 & 0.619 & 0.603 \\
$\mathrm{HFC}$ & 0.618 & 0.559 & 0.512 & 0.606 & 0.581 \\
$\mathrm{~N}_{2} \mathrm{O}$ & 1.566 & 0.645 & 0.535 & 0.797 & 0.786 \\
$\mathrm{NH}_{3}$ & 1.681 & 0.781 & 0.676 & 1.076 & 1.060 \\
$\mathrm{NOx}_{\mathrm{OC}}$ & 1.538 & 0.662 & 0.606 & 0.826 & 0.771 \\
$\mathrm{PFC}$ & 2.062 & 0.792 & 0.706 & 1.069 & 1.112 \\
$\mathrm{SF}_{6}$ & 0.649 & 0.576 & 0.441 & 0.600 & 0.764 \\
$\mathrm{Sulfur}$ & 0.754 & 0.653 & 0.499 & 0.762 & 0.809 \\
VOCs & 0.819 & 0.570 & 0.494 & 0.658 & 0.637 \\
\hline Mean & 2.223 & 0.812 & 0.708 & 1.056 & 1.007 \\
\hline
\end{tabular}

the results indicates that this result is statistically significant for the data as a whole (relative $t$-test statistic 376, $p=$ 0.00007), although when considering each of the crunchers individually, only the RMS-closest and time-dependent ratio crunchers are significantly better with $\mathrm{CH}_{4}$ than $\mathrm{CO}_{2}(p$ values for time-dependent ratio $=0.012, \mathrm{QRW}=0.48$, RMS closest $=0.041$, linear interpolation $=0.060, \mathrm{EQW}=0.39$ ). We therefore conclude that using either $\mathrm{CO}_{2}$ or $\mathrm{CH}_{4}$ as the default will produce the most reasonable results when us- 
Table 5. Root mean squared error in reconstructing known data using different crunchers, with $\mathrm{CH}_{4}$ as the lead variable, normalised by the standard deviation at that time.

\begin{tabular}{lrrrrr}
\hline & $\begin{array}{r}\text { Time- } \\
\text { dependent } \\
\text { ratio }\end{array}$ & QRW & $\begin{array}{r}\text { RMS } \\
\text { Closest }\end{array}$ & $\begin{array}{r}\text { Linear } \\
\text { Inter- } \\
\text { polation }\end{array}$ & EQW \\
\hline $\mathrm{BC}$ & 1.082 & 0.729 & 0.657 & 0.971 & 0.875 \\
$\mathrm{CO}$ & 1.410 & 0.798 & 0.642 & 1.017 & 1.018 \\
$\mathrm{CO}_{2}$ & 0.626 & 0.468 & 0.448 & 0.541 & 0.483 \\
$\mathrm{~F}$ gases & 0.659 & 0.565 & 0.506 & 0.657 & 0.664 \\
$\mathrm{HFC}$ & 0.697 & 0.593 & 0.471 & 0.669 & 0.649 \\
$\mathrm{~N}_{2} \mathrm{O}$ & 0.719 & 0.457 & 0.364 & 0.497 & 0.441 \\
$\mathrm{NH}_{3}$ & 1.134 & 0.756 & 0.533 & 0.958 & 1.048 \\
$\mathrm{NOx}_{\mathrm{OC}}$ & 0.919 & 0.680 & 0.625 & 0.823 & 0.758 \\
$\mathrm{PFC}$ & 1.318 & 0.777 & 0.584 & 0.972 & 0.989 \\
$\mathrm{SF}$ & 0.592 & 0.546 & 0.312 & 0.550 & 0.702 \\
$\mathrm{Sulfur}$ & 0.703 & 0.633 & 0.502 & 0.768 & 0.799 \\
VOCs & 0.610 & 0.580 & 0.508 & 0.627 & 0.644 \\
\hline Mean & 1.398 & 0.802 & 0.618 & 0.972 & 1.038 \\
\hline
\end{tabular}

ing one infiller species, with $\mathrm{CH}_{4}$ performing slightly better while also generally having a slightly lower availability of data.

We perform similar pairwise Wilcoxon $t$ tests on the results of different crunchers and find that the ordering of mean errors (RMS closest $<\mathrm{QRW}<$ linear interpolation $\approx \mathrm{EQW}$ $<$ time-dependent ratio) is statistically robust. The $p$ values are $<0.01$ for almost all pairs except linear interpolation and EQW, which are much greater than 0.1 whether the comparison uses $\mathrm{CO}_{2}$ lead data, $\mathrm{CH}_{4}$ lead data, or all data combined. The one pairwise exception to this is time-dependent ratio and $\mathrm{EQW}$ for $\mathrm{CH}_{4}$, which has only $p=0.028$, though the values for other combinations still have $p<0.01$.

We stress that this does not always mean that the RMSclosest technique is the best default, as it makes the assumption that the pathway being infilled is similar to a whole pathway found in the database. The advantage of the quantilerolling-windows technique is its choice of conservativity for example, it tends to produce values more towards the median value if the default 0.5 quantile is used - and time independence, whereas RMS closest is better at reconstructing the data and has better consistency over time. Linear interpolation, EQW, and the time-dependent ratio are best used in cases in which there is a large degree of knowledge about the expected relationship between variables.

\section{Use cases}

Data in the Silicone examples package rely on the IAMC pyam open-source software data structure (Gidden and Huppmann, 2019) and fit into the IAMC scenario assessment pipeline prepared in support of the IPCC AR6 literature assessment.

As part of the pipeline, emissions projections are also harmonised, i.e. modified to be consistent with known historical emissions in a smooth way (Gidden et al., 2018). The Silicone process is assumed to be part of the IAMC pipeline after harmonisation, as the harmonisation process will potentially differently affect the target and infiller data, resulting in inconsistencies. All infiller options except the latest time ratio are designed such that if both the data being infilled (the "target data") and the data drawn on for infilling ("infiller data") are harmonised, the result must also be harmonised, so there is no need for harmonisation again after infilling. (Latest time ratio only preserves the harmonisation of the last time point in the infiller database.) The infilled results can then be run via climate models, most easily via the OpenSCM package (Nicholls et al., 2020).

We now demonstrate several uses of the package for specific purposes. The notebooks demonstrating the steps for these calculations can be found in the Silicone_examples GitHub repository (Lamboll, 2020), along with several other use cases.

\subsection{Infilling the IMAGE model POEM scenario B}

To demonstrate the uses of this package alone, we will apply the methods directly using unharmonised data in the SR1.5 repository (Huppmann et al., 2019) to infill the emission pathways of the POEM scenario B from the AR5 database (Clarke et al., 2014). The POEM scenarios only report $\mathrm{CO}_{2}$ from certain sources and are thus an excellent use case. The crunchers are all used via the multiple infiller, infill_all_required_emissions_for_openscm. No active decisions are taken except to use the SSP2 scenarios from the MESSAGE model for the specified model interpolation. The choice of SSP2 in this case is ultimately arbitrary but supported by POEM scenario B in being fairly middle of the road and usually fitting in the SSP2 range. The choice of MESSAGE model is because this is the marker model for SSP2 (Riahi et al., 2017). Other POEM scenarios would need different ranges of scenarios for infilling.

We see from Fig. 3 that the linear interpolation model (without filtering the database) provides a chaotic pathway due to its value being determined only by the two points either side of it in the database, which changes semi-randomly with time and should not be used here. Although the "interpolate specified model" approach is also determined by only a few model-scenario pairs because there are only data from a small number of related scenarios, the pathway is smoother and more consistent. The EQW pathway assumes a 

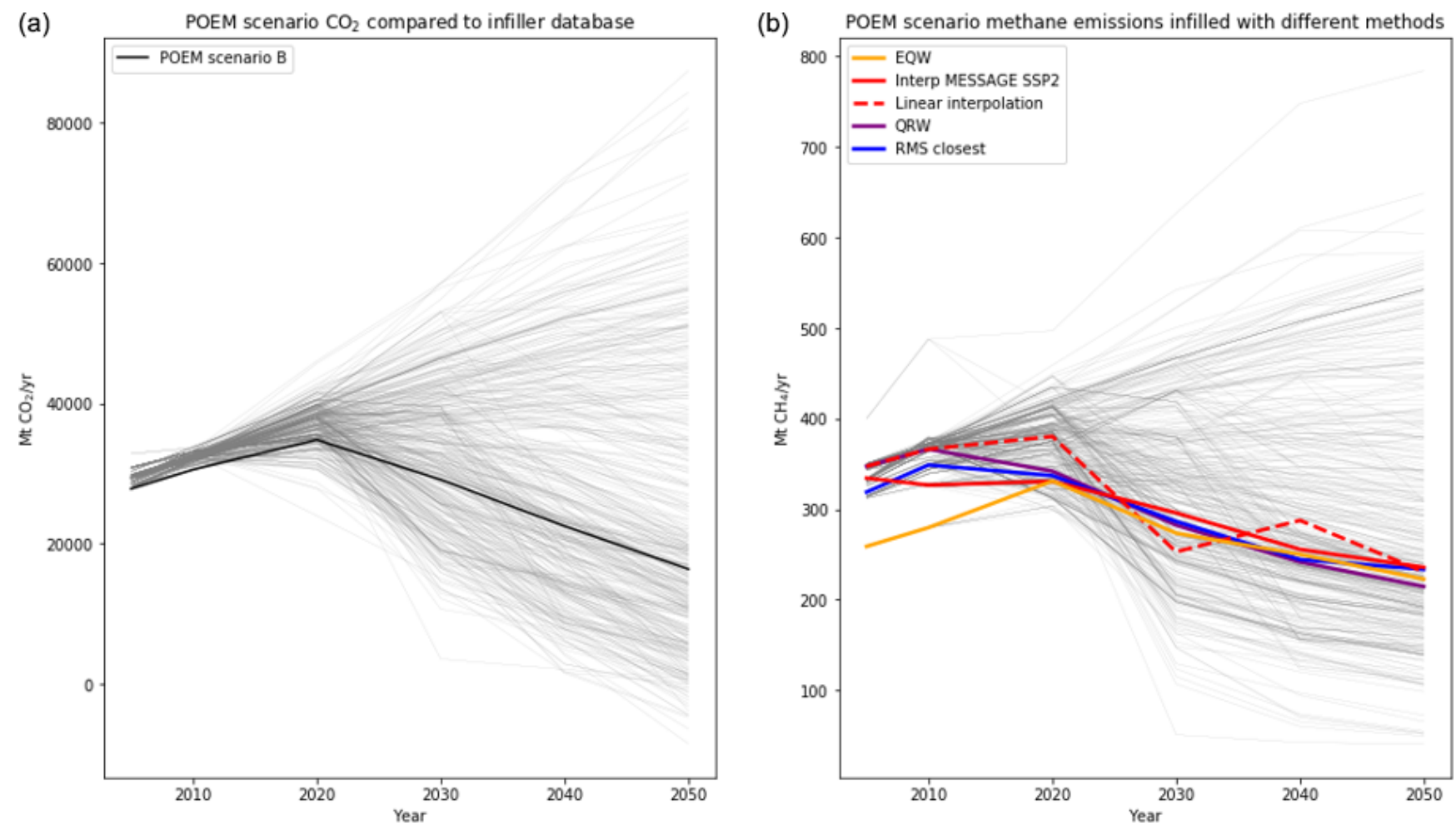

Figure 3. (a) The POEM scenario $B$ projection for $\mathrm{CO}_{2}$ from energy and industrial applications data. The fine lines represent the different time series in the SR1.5 database used to perform the infilling and are not included in the legend for clarity. (b) The results of interpolating these data using five different crunchers. The "interpolate specified model" approach used the MESSAGE model and only chose scenarios based on SSP2.

strong, direct relationship between $\mathrm{CO}_{2}$ and $\mathrm{CH}_{4}$ emissions, which the other crunchers do not uphold at early times, although this would disappear if the data were harmonised. The other cruncher results are all fairly similar and look consistent. The RMS-closest pathway is consistent by construction (and precisely overlines a point in the original database). The quantile-rolling-windows result also looks consistent and tends to move closer to dense clouds of values in the infiller database. In deciding which is the best infiller to use, the RMS-closest result is more consistent over time but more arbitrary in its selection of the pathway, while quantile rolling windows is more conservative in the sense of giving results closer to the median behaviour of the whole dataset.

\subsection{Splitting up a Kyoto greenhouse gas path}

The Silicone package has features that can split a basket of gases into its constituents. In this example we take data from the Climate Action Tracker (CAT) website (https:// climateactiontracker.org/, last access: 9 July 2020; Climate Action Tracker, 2020), which reports projected global emissions in terms of Kyoto gas totals, shown in Fig. 4. While it is possible to use this to infill all other values directly as above, the subcategories of Kyoto gas will not necessarily add up to the Kyoto gas total. Therefore, one of the multiple infillers designed for this use is preferable. The symmetric way to divide the basket into its constituent parts $\left(\mathrm{CO}_{2}, \mathrm{CH}_{4}\right.$, $\mathrm{N}_{2} \mathrm{O}$, and $\mathrm{F}$ gases) is using the "decompose collection with time-dependent ratio" multiple infiller, which uses a ratiobased technique to ensure conservation of the total amounts. Alternatively, the "split collection with remainder" multiple infiller can estimate the fractions of $\mathrm{CH}_{4}, \mathrm{~N}_{2} \mathrm{O}$, and $\mathrm{F}$ gases, then assign the remainder to $\mathrm{CO}_{2} . \mathrm{F}$ gases could be further subdivided using similar methods.

As can be seen in Fig. 5, the curves that result from "decompose collection" are generally smooth, in spite of being separately calculated at each time point. It is important to ensure that the number of scenarios reported at each time are consistent. In the SR1.5 database, some scenarios only report values at decadal intervals, whereas others use 5-year intervals. We interpolated all models to 5-year intervals to give consistent representation. In the $\mathrm{CH}_{4}$ and $\mathrm{F}$ gases, the lowest orange line is clearly seen to rise discontinuously after 2060. This is the last point before the Kyoto total goes negative. To ensure that the sign of the constituents is correct, the formula only considers data from SR1.5 paths for which the Kyoto total has the same sign as in the data being infilled. In this way, emissions that are unlikely to go negative like $\mathrm{CH}_{4}$ are ensured positive; however, their magnitude increases the more negative the aggregate is. 


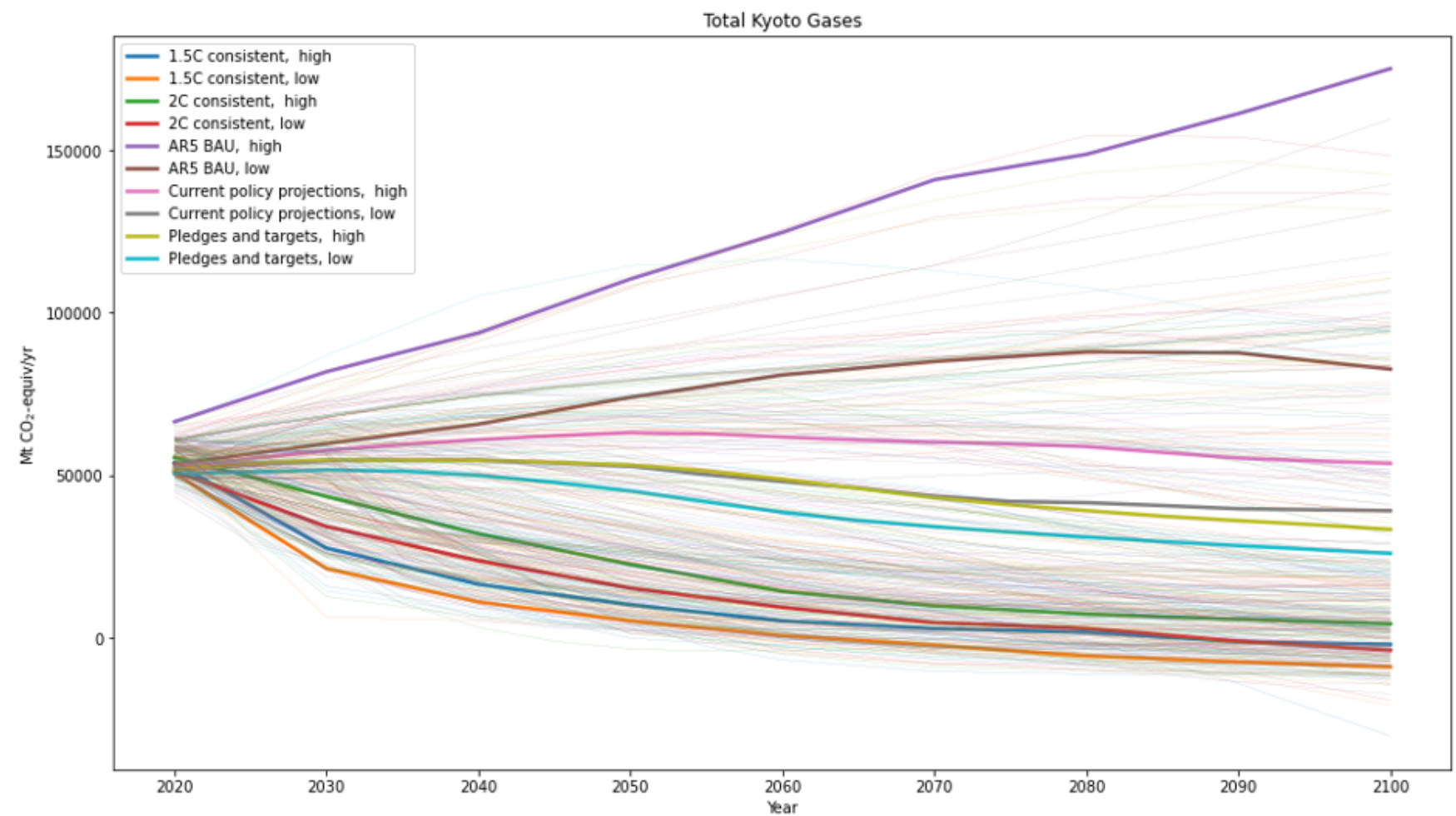

Figure 4. The Climate Action Tracker (CAT) Kyoto gas totals (thick lines) compared with the portfolio of values in the SR1.5 database (thin lines).
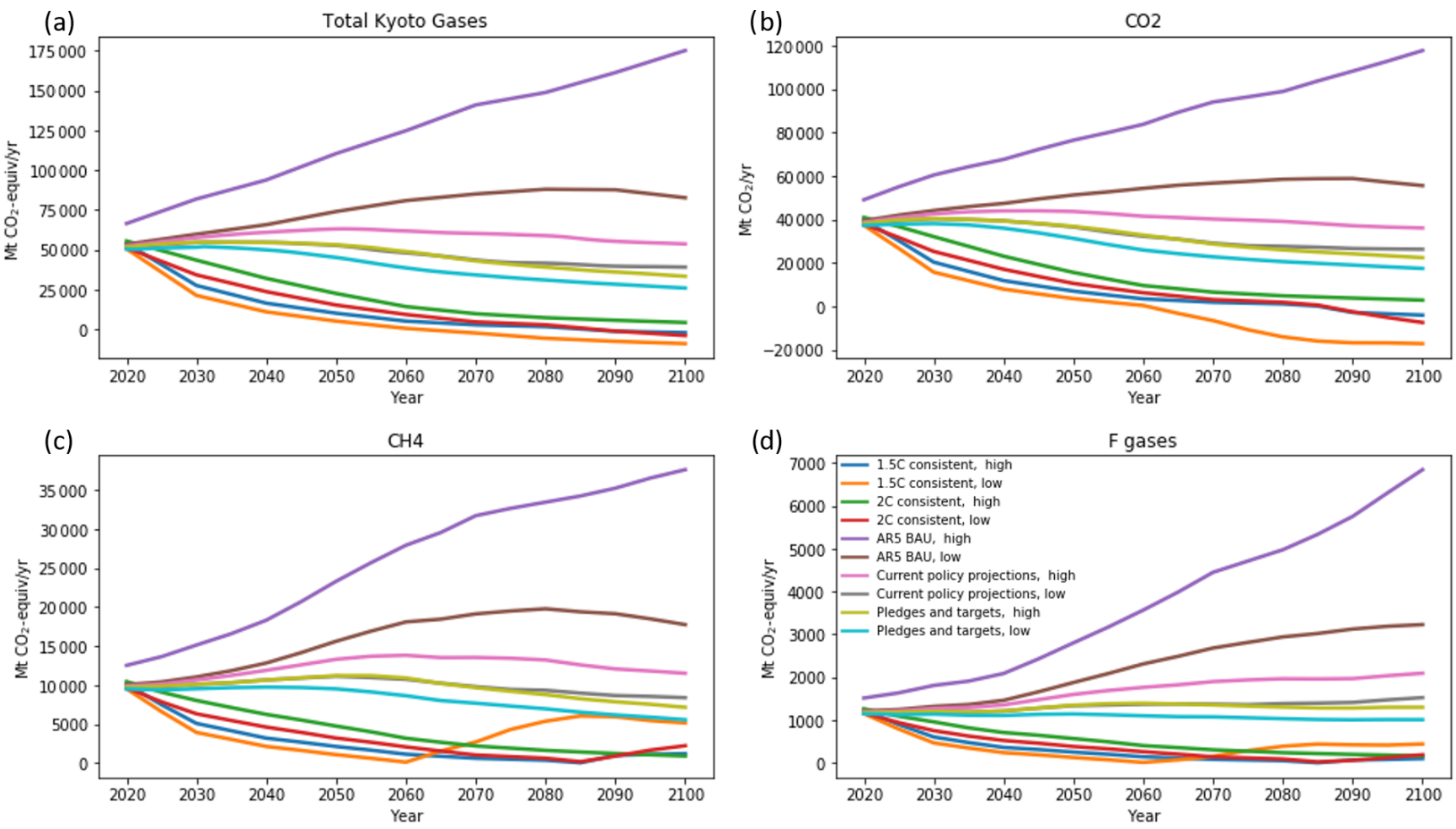

Figure 5. The CAT Kyoto gas baskets decomposed into their components using the decompose collection multiple infiller. 
(a)

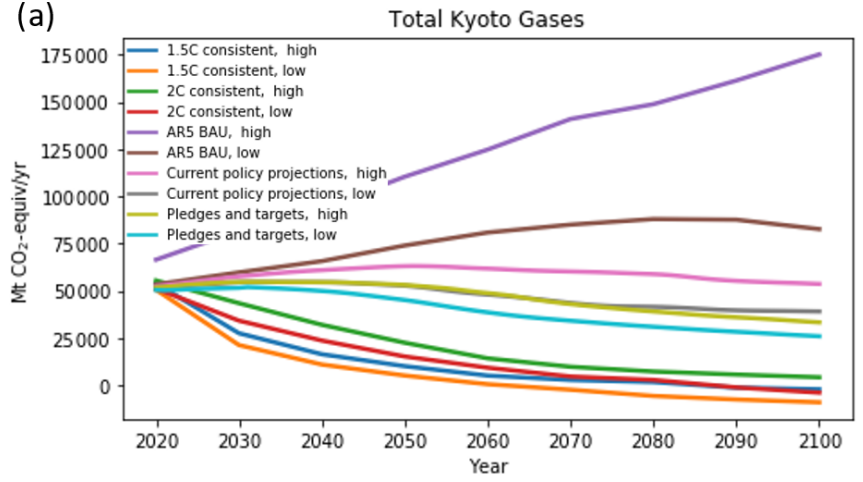

(c)

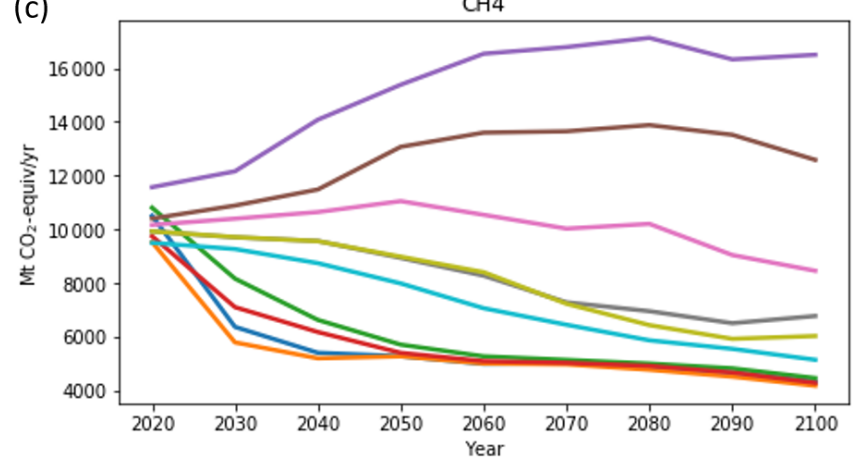

(b)

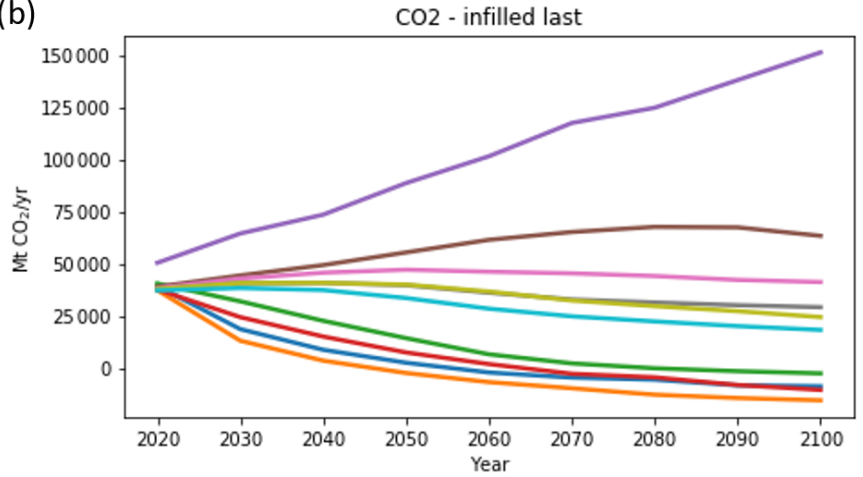

(d)

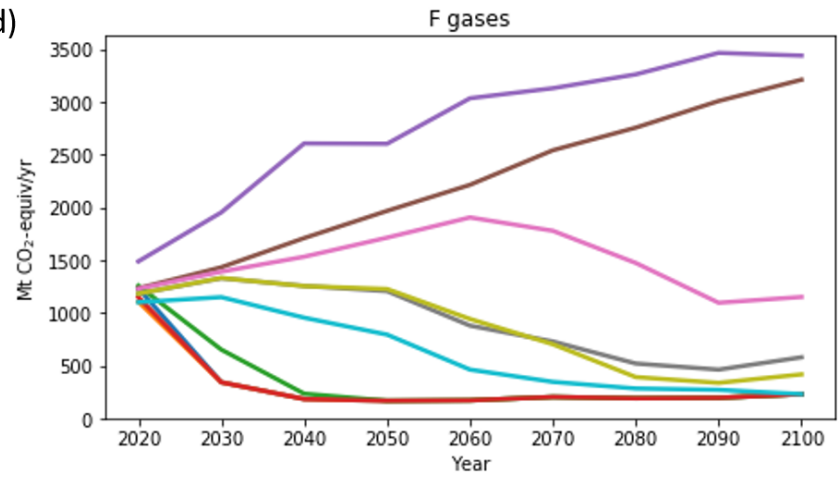

Figure 6. Kyoto gases decomposed by first infilling the non-negative emissions using the (non-ratio) quantile rolling windows, then infilling the $\mathrm{CO}_{2}$ using infill composite values.

For this reason, the "split collection with remainder" method produces more robust results with sign changes in the lead variable. This technique can use any cruncher, usually RMS closest or (probably non-ratio) quantile rolling windows, to infill the positive values and then allow the value that may be negative $\left(\mathrm{CO}_{2}\right)$ to make up the rest. This produces the results seen in Fig. 6. Here the behaviour of all curves is fairly smooth, with no obvious features around zero-crossing points and no negative values except in $\mathrm{CO}_{2}$, as expected.

\subsection{Stylised trajectories}

Another use of this software is to infill simple, stylised trajectories generated to explore a wide range of possibilities without detailed economic modelling. For example, Sanderson et al. (2016) suggest simple formulae whereby one may construct emissions trajectories characterised by a few free variables - in this case, based on rates of transition between the RCPs and a long-term emissions value. They present general formulae for generating plausible total $\mathrm{CO}_{2}$ pathways with several free variables. Silicone provides an alternative means of complementing such results - instead of specifying the functional forms of all emissions, you can have a few key emissions prescribed and infill the remainder using scenarios with similarities to the desired narrative. A notebook can be found in the Silicone examples on GitHub de- tailing the calculations and demonstrating this usage, titled Infill_stylised_path.ipynb (Lamboll, 2020), using data from Riahi et al. (2011) and van Vuuren et al. (2011). It shows that curves with different values in some of the parameters, termed $E_{\infty}$ and $\tau$, can be complemented using a number of techniques. Here we highlight the method of interpolating results from any of the SSP scenarios as implemented by variants of the MESSAGE model. As the different SSPs have different narratives, this allows the user to decide what narrative is relevant to the infilling, rather than adding more arbitrary values (Gidden et al., 2019). An example of this output can be found in Fig. 7.

\section{Summary}

In this paper we have outlined the features of the open-source Silicone package. This provides tools for complementing emissions pathways with other climate-relevant emissions through relationships found in the scenario literature. The package features several scripts for analysing data to establish the relationships between the variables in the complete infiller database to establish the best variables to use when infilling. The values of the follower data are estimated using objects called crunchers. Notebooks describing the use of the crunchers are included in a GitHub repository (https://github.com/GranthamImperial/silicone, last access: 

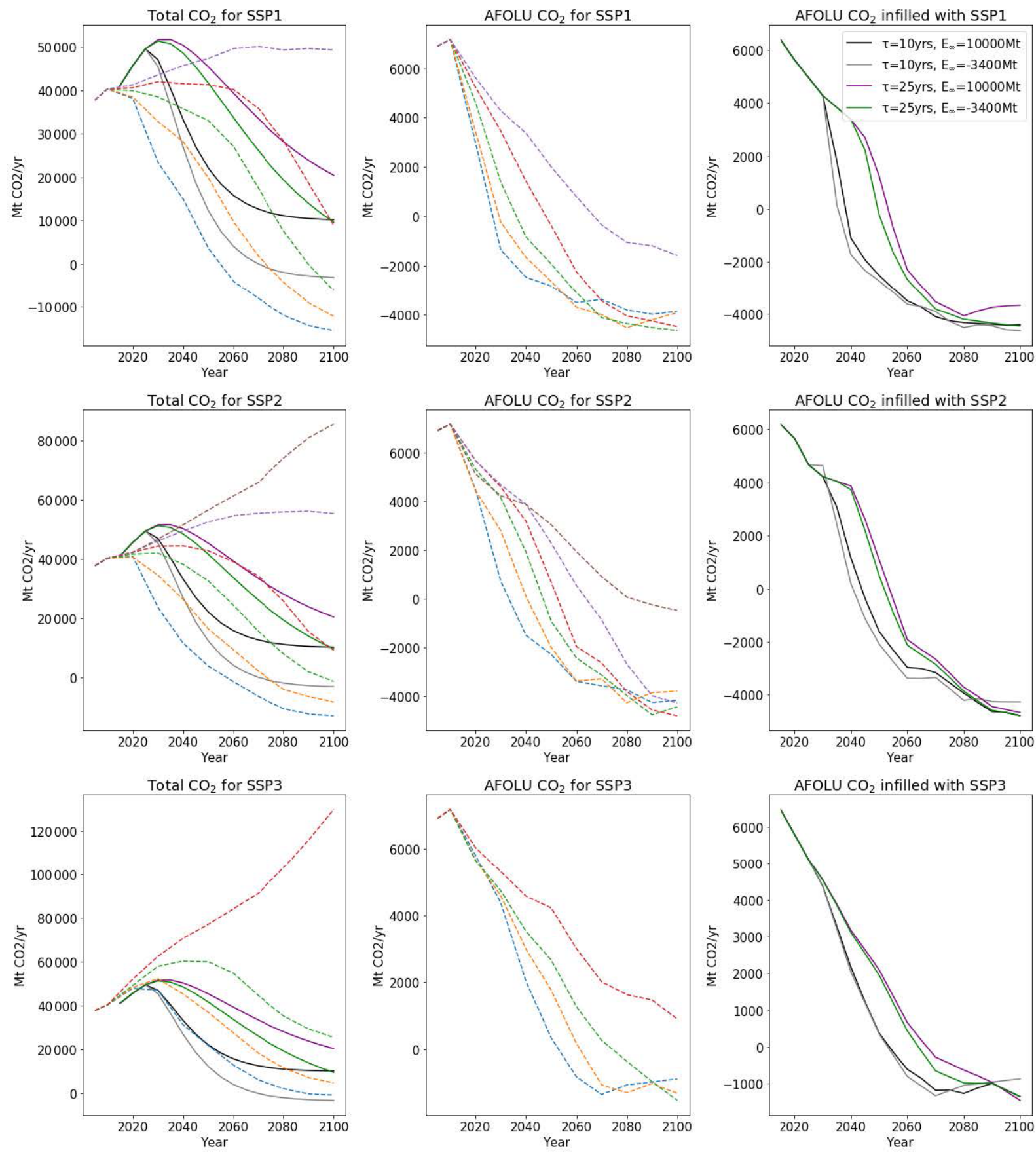

Figure 7. Illustration of using the "interpolate specified scenario" cruncher to infill a series of stylised trajectories (solid lines) characterised by two different parameters ( $\tau$ and $E_{\infty}$ ), as defined in (Sanderson et al., 2016). The first column compares the total $\mathrm{CO}_{2}$ calculated for the stylised trajectories to the values of the MESSAGE model for a given group of SSP scenarios (dotted lines). These are our lead values in each case. The second column shows the range of follower values for that SSP. The third column shows the resultant AFOLU (agriculture, forestry, and other land use) trajectories that emerge from using the "interpolate specified scenario" infiller.

2 November 2020), which also contains full documentation. In addition, a flow chart to guide the choice of cruncher for a given situation is included in the text. The results of Spearman's rank correlations and applying the crunchers to the SR1.5 database implied that the best default lead vari- ables are $\mathrm{CH}_{4}$ and $\mathrm{CO}_{2}$ and that the best default cruncher is the root-mean-squared-closest cruncher, followed by the quantile-rolling-windows cruncher. Both of these crunchers perform significantly better at reconstructing known pathways compared to the commonly used equal quantile walk 
technique, although this and many other crunchers are included in the package for specific situations in which they are more appropriate. Using several examples and use cases of different infilling techniques, this paper has demonstrated that Silicone can easily be used to allow the involvement of a broader range of IAMs in making climate assessments.

Code availability. The Silicone code in this paper is available from the main GitHub repository (Lamboll et al., 2020b). The code used to analyse the output of Silicone is available in a second GitHub repository (Lamboll, 2020).

Author contributions. JR initiated the research based on earlier work by MM. RDL led the code development and the mathematical translation of infiller methods. RDL and ZRJN wrote the code, and JSK assisted in reviewing it. JR and MM conceived infilling techniques and use cases. RDL wrote the paper, and all authors gave comments and contributed to the final version.

Competing interests. The authors declare that they have no conflict of interest.

Acknowledgements. We thank Nicholai Meinshausen for useful statistics discussions.

Financial support. This project has received funding from the European Union's Horizon 2020 research and innovation programme under grant agreement no. 820829 (CONSTRAIN).

Review statement. This paper was edited by Rolf Sander and reviewed by two anonymous referees.

\section{References}

Clarke, L., Jiang, K., Akimoto, K., Babiker, M., Blanford, G., Fisher-Vanden, K., Hourcade, J.-C., Krey, V., Kriegler, E., Löschel, A., McCollum, D., Paltsev, S., Rose, S., Shukla, P. R., Tavoni, M., van der Zwaan, B., and van Vuuren, D.: Assessing Transformation Pathways, in Climate Change 2014: Mitigation of Climate Change, Contribution of Working Group III to the Fifth Assessment Report of the Intergovernmental Panel on Climate Change, edited by: Edenhofer, O., Pichs-Madruga, R., Sokona, Y., Farahani, E., Kadner, S., Seyboth, K., Adler, A., Baum, I., Brunner, S., Eickemeier, P., Kriemann, B., Savolainen, J., Schlömer, S., von Stechow, C., Zwickel, T., and Minx, J. C., Cambridge University Press, 413-510, 2014.

Climate Action Tracker: Climate Action Tracker, available at: https: //climateactiontracker.org/, last access: 9 July 2020.

Gidden, M. J. and Huppmann, D.: pyam: a Python Package for the Analysis and Visualization of Models of the Interaction of
Climate, Human, and Environmental Systems, J. Open Source Softw., 4, 1095, https://doi.org/10.21105/joss.01095, 2019.

Gidden, M. J., Fujimori, S., van den Berg, M., Klein, D., Smith, S. J., van Vuuren, D. P., and Riahi, K.: A methodology and implementation of automated emissions harmonization for use in Integrated Assessment Models, Environ. Model. Softw., 105, 187200, https://doi.org/10.1016/j.envsoft.2018.04.002, 2018.

Gidden, M. J., Riahi, K., Smith, S. J., Fujimori, S., Luderer, G., Kriegler, E., van Vuuren, D. P., van den Berg, M., Feng, L., Klein, D., Calvin, K., Doelman, J. C., Frank, S., Fricko, O., Harmsen, M., Hasegawa, T., Havlik, P., Hilaire, J., Hoesly, R., Horing, J., Popp, A., Stehfest, E., and Takahashi, K.: Global emissions pathways under different socioeconomic scenarios for use in CMIP6: a dataset of harmonized emissions trajectories through the end of the century, Geosci. Model Dev., 12, 14431475, https://doi.org/10.5194/gmd-12-1443-2019, 2019.

Gütschow, J., Jeffery, M. L., Schaeffer, M., and Hare, B.: Extending Near-Term Emissions Scenarios to Assess Warming Implications of Paris Agreement NDCs, Earth's Futur., 6, 1242-1259, https://doi.org/10.1002/2017EF000781, 2018.

Huppmann, D., Rogelj, J., Kriegler, E., Krey, V., and Riahi, K.: A new scenario resource for integrated $1.5^{\circ} \mathrm{C}$ research, Nat. Clim. Chang., 8, 1027-1030, https://doi.org/10.1038/s41558018-0317-4, 2018.

Huppmann, D., Kriegler, E., Krey, V., Riahi, K., Rogelj, J., Calvin, K., Humpenoeder, F., Popp, A., Rose, S. K., Weyant, J., Bauer, N., Bertram, C., Bosetti, V., Doelman, J., Drouet, L., Emmerling, J., Frank, S., Fujimori, S., Gernaat, D., Grubler, A., Guivarch, C., Haigh, M., Holz, C., Iyer, G., Kato, E., Keramidas, K., Kitous, A., Leblanc, F., Liu, J.-Y., Löffler, K., Luderer, G., Marcucci, A., McCollum, D., Mima, S., Sands, R. D., Sano, F., Strefler, J., Tsutsui, J., Van Vuuren, D., Vrontisi, Z., Wise, M., and Zhang, R.: IAMC $1.5^{\circ} \mathrm{C}$ Scenario Explorer and Data, IIASA, Integr. Assess. Model. Consort. Int. Inst. Appl. Syst. Anal., https://doi.org/10.5281/zenodo.3363345, 2019.

Lamboll, R. D.: GranthamImperial/silicone_examples (Version v1.0.0)., Zenodo, https://doi.org/10.5281/zenodo.4020372, 2020.

Lamboll, R. D., Nicholls, Z., and Kikstra, J.: Silicone documentation, available at: https://silicone.readthedocs.io/en/latest/index. html, last access: 11 May 2020a.

Lamboll, R. D., Nicholls, Z., and Kikstra, J.: Silicone (Version v1.0.0), Zenodo, https://doi.org/10.5281/zenodo.3822259, 2020b.

McKinney, W.: pandas: a Foundational Python Library for Data Analysis and Statistics, Python High Perform. Sci. Comput., 2011.

Meinshausen, M. and Dooley, K.: Mitigation scenarios for nonenergy GHG, in Achieving the Paris Climate Agreement Goals: Global and Regional $100 \%$ Renewable Energy Scenarios with Non-Energy GHG Pathways for $+1.5^{\circ} \mathrm{C}$ and $+2{ }^{\circ} \mathrm{C}$, Springer International Publishing, 79-91, 2019.

Meinshausen, M., Hare, B., Wigley, T. M. L., Van Vuuren, D., Den Elzen, M. G. J., and Swart, R.: Multi-gas emissions pathways to meet climate targets, Clim. Change, 75, 151-194, https://doi.org/10.1007/s10584-005-9013-2, 2006.

Meinshausen, M., Raper, S. C. B., and Wigley, T. M. L.: Emulating coupled atmosphere-ocean and carbon cycle models with a simpler model, MAGICC6 - Part 1: Model descrip- 
tion and calibration, Atmos. Chem. Phys., 11, 1417-1456, https://doi.org/10.5194/acp-11-1417-2011, 2011.

Meinshausen, M., Vogel, E., Nauels, A., Lorbacher, K., Meinshausen, N., Etheridge, D. M., Fraser, P. J., Montzka, S. A., Rayner, P. J., Trudinger, C. M., Krummel, P. B., Beyerle, U., Canadell, J. G., Daniel, J. S., Enting, I. G., Law, R. M., Lunder, C. R., O’Doherty, S., Prinn, R. G., Reimann, S., Rubino, M., Velders, G. J. M., Vollmer, M. K., Wang, R. H. J., and Weiss, R.: Historical greenhouse gas concentrations for climate modelling (CMIP6), Geosci. Model Dev., 10, 2057-2116, https://doi.org/10.5194/gmd-10-2057-2017, 2017.

Nabel, J. E. M. S., Rogelj, J., Chen, C. M., Markmann, K., Gutzmann, D. J. H., and Meinshausen, M.: Decision support for international climate policy - The PRIMAP emission module, Environ. Model. Softw., 26, 1419-1433, https://doi.org/10.1016/j.envsoft.2011.08.004, 2011.

Nicholls, Z., Gieseke, R., Lewis, J., and Willner, S.: OpenSCM: Unified access to simple climate models, available at: https: //github.com/openscm/openscm, last access: 6 April 2020.

O’Neill, B. C., Tebaldi, C., van Vuuren, D. P., Eyring, V., Friedlingstein, P., Hurtt, G., Knutti, R., Kriegler, E., Lamarque, J.-F., Lowe, J., Meehl, G. A., Moss, R., Riahi, K., and Sanderson, B. M.: The Scenario Model Intercomparison Project (ScenarioMIP) for CMIP6, Geosci. Model Dev., 9, 3461-3482, https://doi.org/10.5194/gmd-9-3461-2016, 2016.

Riahi, K., Rao, S., Krey, V., Cho, C., Chirkov, V., Fischer, G., Kindermann, G., Nakicenovic, N., and Rafaj, P.: RCP 8.5-A scenario of comparatively high greenhouse gas emissions, Clim. Change, 109, 33, https://doi.org/10.1007/s10584-011-0149-y, 2011.

Riahi, K., van Vuuren, D. P., Kriegler, E., Edmonds, J., O’Neill, B. C., Fujimori, S., Bauer, N., Calvin, K., Dellink, R., Fricko, O., Lutz, W., Popp, A., Cuaresma, J. C., KC, S., Leimbach, M., Jiang, L., Kram, T., Rao, S., Emmerling, J., Ebi, K., Hasegawa, T., Havlik, P., Humpenöder, F., Da Silva, L. A., Smith, S., Stehfest, E., Bosetti, V., Eom, J., Gernaat, D., Masui, T., Rogelj, J., Strefler, J., Drouet, L., Krey, V., Luderer, G., Harmsen, M., Takahashi, K., Baumstark, L., Doelman, J. C., Kainuma, M., Klimont, Z., Marangoni, G., Lotze-Campen, H., Obersteiner, M., Tabeau, A., and Tavoni, M.: The Shared Socioeconomic Pathways and their energy, land use, and greenhouse gas emissions implications: An overview, Glob. Environ. Chang., 42, 153-168, https://doi.org/10.1016/j.gloenvcha.2016.05.009, 2017.

Robiou du Pont, Y. and Meinshausen, M.: Warming assessment of the bottom-up Paris Agreement emissions pledges, Nat. Commun., 9, 1-10, https://doi.org/10.1038/s41467-018-072239, 2018

Rogelj, J., Rao, S., McCollum, D. L., Pachauri, S., Klimont, Z., Krey, V., and Riahi, K.: Air-pollution emission ranges consistent with the representative concentration pathways, Nat. Clim. Chang., 4, 446-450, https://doi.org/10.1038/nclimate2178, 2014.
Rogelj, J., Shindell, D., Jiang, K., Fifita, S., Forster, P., Ginzburg, V., Handa, C., Kheshgi, H., Kobayashi, S., Kriegler, E., Mundaca, L., Séférian, R., and Vilariño, M. V.: Mitigation pathways compatible with $1.5^{\circ} \mathrm{C}$ in the context of sustainable development, chap. 2, in: Global Warming of $1.5^{\circ} \mathrm{C}$, edited by: Flato, G., Fuglestvedt, J., Mrabet, R., and Schaeffer, R., IPCC Special Report, 93-174, available at: http://www.ipcc.ch/report/sr15/ (last access: 2 November 2020), 2018a.

Rogelj, J., Popp, A., Calvin, K. V., Luderer, G., Emmerling, J., Gernaat, D., Fujimori, S., Strefler, J., Hasegawa, T., Marangoni, G., Krey, V., Kriegler, E., Riahi, K., Van Vuuren, D. P., Doelman, J., Drouet, L., Edmonds, J., Fricko, O., Harmsen, M., Havlík, P., Humpenöder, F., Stehfest, E., and Tavoni, M.: Scenarios towards limiting global mean temperature increase below $1.5^{\circ} \mathrm{C}$, Nat. Clim. Chang., 8, 325-332, https://doi.org/10.1038/s41558018-0091-3, 2018b.

Sanderson, B. M., O’Neill, B. C., and Tebaldi, C.: What would it take to achieve the Paris temperature targets?, Geophys. Res. Lett., 43, 7133-7142, https://doi.org/10.1002/2016GL069563, 2016.

Schaeffer, M., Gohar, L., Kriegler, E., Lowe, J., Riahi, K., and van Vuuren, D.: Mid- and long-term climate projections for fragmented and delayed-action scenarios, Technol. Forecast. Soc. Change, 90, 257-268, https://doi.org/10.1016/j.techfore.2013.09.013, 2015.

Smith, C. J., Forster, P. M., Allen, M., Leach, N., Millar, R. J., Passerello, G. A., and Regayre, L. A.: FAIR v1.3: a simple emissions-based impulse response and carbon cycle model, Geosci. Model Dev., 11, 2273-2297, https://doi.org/10.5194/gmd-11-2273-2018, 2018.

Teske, S., Pregger, T., Simon, S., Naegler, T., Pagenkopf, J., van den Adel, B., Meinshausen, M., Dooley, K., Briggs, C., Dominish, E., Giurco, D., Florin, N., Morris, T., and Nagrath, K.: Methodology, in: Achieving the Paris Climate Agreement Goals, Springer International Publishing, 25-78, 2019.

van Vuuren, D. P., Edmonds, J., Kainuma, M., Riahi, K., Thomson, A., Hibbard, K., Hurtt, G. C., Kram, T., Krey, V., Lamarque, J. F., Masui, T., Meinshausen, M., Nakicenovic, N., Smith, S. J., and Rose, S. K.: The representative concentration pathways: An overview, Clim. Change, 109, 5-31, https://doi.org/10.1007/s10584-011-0148-z, 2011.

Weyant, J.: Some contributions of integrated assessment models of global climate change, Rev. Environ. Econ. Policy, 11, 115-137, https://doi.org/10.1093/reep/rew018, 2017. 